\title{
Improving Physical Fitness in Individuals with Autism Spectrum with Game Console Physical Activity Program
}

\section{Oyun Konsollu Fiziksel Aktivite Programı ile Otizm Spektrumundaki Bireylerde Fiziksel Uygunluğun Geliştirilmesi}

\section{Yeşim Gökgöz ${ }^{1}$}

(iD) http://orcid.org/0000-0002-2804-6655

Institute of Health Sciences, Marmara University, Istanbul, Turkey

\author{
Mehmet Ata Öztürk \\ iD http://orcid.org/0000-0002-7755-7654 \\ Department of Physical Education and Sports, Middle East Technical University, Ankara, Turkey
}

\section{Salih Pınar \\ (iD http://orcid.org/0000-0001-8399-7835}

Faculty of Sport Sciences, Marmara University, Istanbul, Turkey

\begin{abstract}
The aim of this study was to investigate the effects of game consoles on the physical fitness levels of young individuals with autism spectrum disorders. Sample consisted of 8 individuals (4 male, 4 female), aged 11-18 years who were attending a sports training center. $A B A B$ - multiple baseline across participants, single case research design was used. Overall study period was 14 weeks and the minimum research group participation period was 12 weeks. Camera was used to record the activities. The alternative treatment groups were given a routine training program that is provided by the center. The experiment group received an adapted physical activity training program using the kinect game console. Eurofit test battery was used for physical fitness assessments. Pre-test post-test measures were reported regarding the physical fitness levels. Considering the evaluated results; The average percentage of the percentage increase in the Flamingo equilibrium test was $60.15 \%$, the average of the increase percentage in the elasticity measurement results was 62.39, the mean percentage of the increase in body strength test was $45.46 \%$, the average of the increase in running speed was $12.37 \%$, the average of the increase in durability was $43.14 \%$. Findings show significant improvements on the
\end{abstract}

${ }^{1}$ Corresponding author: Yeşim Gökgöz

Sağlık Bilimleri Enstitüsü, Enstitüler Binası 4. Kat, Marmara Üniversitesi Göztepe Yerleşkesi Kadıköy, İstanbul yesimgokgoz@hotmail.com 
physical fitness levels of participants in the experimental group (console training) in contrast to the alternative treatment group (routine program).

Keywords: Autism spectrum disorders, game console training, physical activity, fitness levels.

\section{Öz}

Bu araştırmanın amacı, Otizm Spektrum Bozukluğu olan (OSB'li) bireylerin katıldığı oyun konsollu uyarlanmış fiziksel aktivite antrenman programının; fiziksel uygunluğa etkilerini belirlemektir. Araştırma grubu 11-18 yaş aralığında olan sekiz OSB'li bireylerden oluşmuştur. Sporcular araştırma başlamadan önce de merkezde spor yapmakta olan 8 kişilik 4'ü erkek 4'ü kadın OSB'li bireylerdir. 8 kişilik bu grup rastgele seçilen 4'er kişilik kadın ve erkek gruplarından oluşmaktadır. Antrenmanların programlanması sürecinde araştırma yöntemi olarak Tek Denekli Araştırma Yöntemlerinden ABAB modeli kullanılmıştır. Araştırmaya alınan bireylere 14 hafta boyunca haftada 4 gün, her gün birer saat olmak üzere haftada 4 saat antrenman yaptırılmıştır. Antrenmanlar çalışmaların yapıldığı alanlarda kameraya çekilmiştir. Kontrol gruplarına standart antrenman programları uygulanırken araştırma gruplarına ise "Oyun konsollu uyarlanmış fiziksel aktivite antrenman programı" isimli özel bir antrenman programı uygulanmıştır. Araştırmada fiziksel uygunluk düzeyleri ile ilgili gelişimler izlenmiş ve değerlendirilmiştir. Fiziksel uygunluk değerlendirmesinde eurofit test bataryası kullanılmıştır. Sporculara ön test son test ölçümleri uygulanarak fiziksel uygunluk düzeyleri de değerlendirilmiştir.Değerlendirilen sonuçlar ele alındığında; Flamingo denge testi artış yüzdesinin ortalaması \%60.15. Esneklik Ölçüm sonuçlarındaki artış yüzdesinin ortalaması \%62.39, Gövde Kuvveti Testi artış yüzdesinin ortalaması \%68.67, Bükülü Kol Asılmada artış yüzdesinin ortalaması \%62.16, Kol Hareketinin Süratindeki artış yüzdesinin ortalaması \%13.84, Durarak Çift Bacak Öne Sıçrama artış yüzdesinin ortalaması \%45.46, Koşu Sürati artış yüzdesinin ortalaması \%12.37, Dayanıklııktaki artış yüzdesinin ortalaması ise \%43.14 gözlemlenmiştir. Sonuç olarak uyarlanmış antrenman programına katılan OSB'li bireylerin fiziksel uygunluk testlerinin sonuçları incelendiğinde sonuçlarda artan bir fark olduğu ve farkın uyarlanmış antrenman programı uygulaması lehine anlamlı olduğu bulunmuştur.

Anahtar Kelimeler: Otizm Spectrum Bozukluğu, Oyun Konsolu, Fiziksel Aktivite, Fiziksel Uygunluk

\section{Giriş}

OSB, sosyal iletişim ve sosyal etkileşim becerilerinde yetersizlik, sınırlı/yineleyici ilgi ve davranışlar ile karakterize nörogelişimsel bir bozukluk olarak tanımlanmıştır (Amerikan Psikiyatri Derneği [American Psychatric Association], 2013). 2013 yılında yayınlanan Ruhsal Bozuklukların Tanısal ve Sayımsal El Kitabı 5. baskısında (Diagnostic and Statistical Manual of Mental Disorders, 5th edition [DSM-5]) otizm belirtilerinin çocuğun gelişiminin erken dönemlerinde ortaya çıkması, belirtilerin bireyin yaşantısında sosyal, mesleki vb. önemli alanlarda anlamlı düzeyde bozukluğa yol açması ve bu bozukluğun zihinsel yetersizlik veya gelişimsel gerilik sebebi ile olmaması gerektiği belirtilmektedir. OSB ile ilgili belirtilen bu alanlarda yetersizliğe sahip olan bireyler, normal gelişim gösteren akranlarının kendiliğinden öğrendikleri pek çok beceriyi öğrenmek için sistematik bir öğretime ve yapılandırılmış bir öğretim ortamına ihtiyaç duymaktadır (Tekin-iftar ve Değirmenci, 2012).

OSB, ayrıca bireylerin fonksiyonel yaşamları üzerine etki eden; sosyal ilişki, iletişim, davranış ve gelişimsel bozukluğa neden olabilen bir durum olarak da ifade edilmektedir (Cottenceau vd., 2012; Russell, Kelly, Golding, 2010). Bahsedilen bu durumlar OSB olan bireylerin düşük fiziksel aktivite düzeyine sahip olmasına neden olmakta ve boş zamanlarını değerlendirmek için fiziksel aktivite ve spor programlarına katılmasına engel olmaktadır (Lee ve Porretta, 2013). Fiziksel aktivitenin yararları dikkate alındığında, daha sağlıklı bireyler ve daha sağlıklı toplum için, bireylerin en uygun düzeyde fiziksel aktiviteye teşvik edilmeleri gerekmektedir. Fiziksel aktivite, birçok hastalık için hem önleyici hem de iyileştirici etkilere sahiptir (Akyol, Bilgiç ve Ersoy, 2008). Fiziksel aktivite yetersizliği vücut üzerindeki olumsuz etkilerinin yanı sıra, vücut ağırlığında artışa neden olmaktadır (Seabra vd., 2013). Dünya genelinde gün geçtikçe yetersiz fiziksel aktiviteye bağlı olarak artış gösteren aşırı vücut ağırlığı ve obezite, kalp-damar rahatsızlıkları, mental rahatsızlıklar, kas-iskelet yaralanmaları gibi sağlık sorunlarının habercisi niteliğinde olmaktadır (TC Sağlık Bakanlığı, 2014). Fiziksel aktivite, tüm insanlar için sağlıklı yaşam stilinin önemli bir parçası olmasına karşın OSB'li bireylerde sıkça göz ardı edilmiş bir konudur (Penny, 2005). Yine aşırı kilolu olma bazı OSB'li 
bireyler için temel sorunlardan bir tanesidir ve düzenli olarak yapılan fiziksel aktivite bu sorunun önlenmesinde önemli bir rol oynamaktadır (Todd ve Reid, 2006).

OSB'li bireylerde uzamsal farkındalık, beden farkındalığı, sosyal iletişim, akademik ve konuşma becerilerinde bozukluklar gibi güçlükler görülebilmektedir. Bu becerilerin geliştirilmesine yönelik birçok müdahale yöntemi denenmektedir; Ulusal Otizm Merkezi'nin National Autism Center (NAC) 2015 yılında yayınlamış olduğu Ulusal Standartlar Raporu'nda OSB'li bireylere yönelik müdahale yöntemleri çeşitli başlıklar altında sınıflandırılmaktadır. Bu sınıflandırmada OSB'li bireylerle yapılan fiziksel aktivite çalışmaları yeni gelişen uygulamalar içinde yer almaktadır. Egzersiz ve spor aktivitelerine katıımın, OSB'li bireylerin fiziksel ve motor gelişimleri (Pitetti, Rendoff, Grover ve Beets, 2007), bilişsel fonksiyonları (Anderson-Hanley, Turek ve Schneiderman, 2011), steryotipik davranışları (Bahrami, Movahedi, Marandi ve Abedi, 2012) ve akademik becerileri (Nicholson, Kehle, Bray ve Van Heest, 2011) üzerinde olumlu yönde etkisi olduğundan dolayı son derece önemli olduğu vurgulanmaktadır (Menear ve Neumeier, 2015; Srinivasan, Pescatello, Bhat, 2014) Yapılan çalışmalarda tempolu koşunun (Kern, Koegel ve Dunlap, 1984), patenin (Powers, Thibadeau ve Rose, 1992), yüzmenin (Yılmaz, Yanardağ, Birkan ve Bumin, 2004), stretching (germe) egzersizlerinin (Reid, Factor, Freeman ve Sherman, 1988), hidroterapi tedavilerinin (Bumin, Uyanık, Yılmaz, Kayıhan ve Topçu, 2003) OSB tanılı bireylerin fiziksel gelişim sağladığı ve steryotipik hareketlerini azalttığı belirtilmiştir. Bu becerilerin geliştirilmesine yönelik müdahale yöntemlerinden biride uyarlanmış fiziksel aktivitedir.

Günümüzde yapılan birçok araştırma, etkileşimli dijital teknolojik araçlar olan mobil uygulamalar, bilgisayarlar, sanal ve arttııımış gerçeklik ve robotik uygulamalar OSB'li bireylerde dikkat çekici şekilde hareketsiz davranışları azalttığı gözlemlenmiştir (Lee, vd. 2018). Yıllar içinde konsol oyunları eğlence boyutunu aşarak eğitici bir karakter de kazanmıştır. Son dönemde, vücut hareketlerinin oyun kumanda cihazının yerine geçtiği Kinect teknolojisi ile kullanıcının aktif katıımı da hayata geçti. Kinect'in öğrenme sürecinde çeşitli ülkelerde okul uygulama örnekleri de mevcuttur. Bazı araştırmacılar bir adım daha ileri gidiyor ve OSB'li çocuklar için öğrenmeye yardımcı bir araç olarak Kinect kullanımını inceliyorlar, hatta öneriyorlar (Boutsika, 2014).

Lee ve diğerleri tarafından 2012 yılında yapılan çalışmada otizmi olan bireylerin duyusal uyumlarını sağlamak üzere yine Kinect kullanılarak 6-10 yaşları arasında üç otizmi olan çocuk ile çalışıımıştır. Bilgisayara bağlı kamera sistemi ve hareket algılayıcı sensörler ile çalışan oyunlar sistemin temel bileşenleri olarak kullanılmıştır. Bir başka oyun konsollu fiziksel aktivite çalışmasında OSB'li bireylerin eğitiminde Kinect kullanımının etkililiği çocukların kişisel ifadeleri ve belirlenen hedeflere ulaşma durumlarına göre değerlendirilmiş ve Kinect'in otizmi olan çocukların hafıza ve sosyal beceri performans düzeylerini artırmada etkili olduğu belirtilmiştir (Boutsika, 2014). Yapılan benzer çalışmalar bakıldığında OSB'li bireylerin Kinect destekli oyun konsolları ile yapılan fiziksel aktivitelerin, bireyde farklı alanlarda olumlu etkiler yarattığı gözlenmiştir (Altanis vd., 2013; Blair, Davis, 2013; Cardenas vd. 2013; Kamfiroozie, Zohari, Dehbozorgi, 2013; Kadakal, Kıvrak, Köse, 2014). Yaptığımız bu çalışmada da son dönemlerdeki yapılan çalışmaları desteklemek amaçı oyun konsollu fiziksel aktivite uygulamalarının bireylerde oluşturduğu fiziksel uygunluk düzeylerindeki olumlu değişimi gözlemlemektir.

\section{Yöntem}

Araştırmada, Tek Denekli Araştırma Yöntemleri (Single Case Research)'nden "Çoklu Başlama Düzeyi Modeli'nin ABAB tasarımı" kullanıımıştır. Araştırmanın tüm periyodu 14 haftadan oluşmuştur. Bireyler kontrol grubunda Standart antrenmana dahil olmuşlardır. Her hafta bir kadın bir erkek olmak üzere 2 şer kişilik gruplar halinde standart antrenmandan alternatif uygulamaya geçiş yapmışlardır. 4. haftanın sonunda araştırmaya dahil olan tüm bireyler alternatif uygulamaya başlayarak deney grubuna dahil olmuşlardır. Antrenman uygulamalarına başlarken "Oyun konsollu uyarlanmış fiziksel aktivite antrenman programı" isimli özel uyarlanmış bir bireysel antrenman programı kullanımıştır. Bu program ile 11-18 yaş arası OSB'li bireylerde fiziksel uygunluk ile ilgili gelişmeler incelenmiştir. Antrenman programı ile fiziksel uygunluk kazanımları arasında anlamlı bir ilişki olup olmadığı ise Eurofit Test Bataryası ile ön test son test seçkisiz deseni ile değerlendirilmiştir. 
Bu araştırmanın evreni, Ankara ili Çankaya illçesi dernekler masasına bağlı olan bir dernek ve bu derneğin spor kulübünde spor yapan OSB'li bireylerden oluşmaktadır. Çalışmaya dahil olan 8-11 yaş aralığındaki bu örneklem grubu ayrıca, spor yapma açısından herhangi bir sağlık sorunu olmayan, son bir yıl içerisinde en az 3 ay süresince düzenli olarak kinect kullanmış olup ayrıca spor yapmış OSB'li, 4 erkek 4 kız toplam 8 gönüllü tesadüfü yöntem ile seçilmiştir. Çalışmaya alınacak bireylerin dernekte bulunma sürelerinin aynı olmasına dikkat edilmiştir. Katıımcıların tıbbi geçmişinde kronik (diyabet, astım, kronik obstrüktif akciğer hastalığı, hipertansiyon, metabolik sendrom) hastalığın bulunmaması durumları tespit edilerek çalışmaya dahil edilmiștir. Araştırma grubundaki katıımcılara çalışma öncesinde ebeveynleri eşliğinde, Physical Activity Readiness Questionnaire (PARQ) testi değerlendirmesi ve sonrasında American College of Sports Medicine (ACSM) risk faktör analizi değerlendirilmesi yapıımıştır. Bu çalışmaya katılmak isteyen gönüllülere ve ebeveynlerinin hepsine tüm test protokolü anlatılmıştır.

Uluslararası alanyazın incelendiğinde, OSB'li bireyler ve fiziksel aktivite konusunu inceleyen ve araştırmanın yöntemine benzer olan çalışmalarda, tek haneli rakamlar çoğunlukta olmakla birlikte çift haneli sayılarda da örneklem tespit edildiği belirlenmiştir. Bu çalışmalardan birinde Robledo ve Donnellan (2008), OSB'li 5 bireyle, Muller ve diğerleri (2008) de 18 OSB'li bireyle, Ruef ve Turnbull (2002), bir başka engel grubuyla birlikte, OSB'li bireyleri dahil ettiği çalışmasında 4 OSB'li bireyde problem davranışları incelemiştir. Ayrıca Lang ve diğerleri 2010 yılında yaptığı bir meta analiz çalışmasında toplam 18 araştırma incelenmiş ve bu araştırmaların tamamına katılan toplam birey sayısı 64 olarak bildirilmiştir. Sorenson ve Zarret 2014 yılında 19 OSB'li bireyle çalışırken, 2017 yılında Olin ve diğerleri araştırmalarına sadece 7 OSB'li bireyi dahil etmişlerdir.

\section{Bulgular}

Yapılan Eurofit Fiziksel Uygunluk Test Bataryasının sonucunda araştırmaya katılan OSB'li bireylerin fiziksel uygunluk düzeylerinde artış görülmüştür. Bu artışlar Eurofit Test Bataryasının Flamingo Denge Testi artış yüzdesinin ortalaması \%60.15 olarak hesaplanmış, en düşük artış \%33.3 en yüksek artış ise \%100 olarak tespit edilmiştir (Tablo 1). Esneklik Ölçüm sonuçlarındaki artış yüzdesinin ortalaması \%62.39 olarak hesaplanmış, en düşük artış \%25 en yüksek artış ise \%100 olarak tespit edilmiştir (Tablo 2). Gövde Kuvveti Testi artış yüzdesinin ortalaması \%68.67 olarak hesaplanmış, en düşük artış \% 40 en yüksek artış ise \%100 olarak tespit edilmiştir (Tablo 3). Bükülü Kol Asılma da ise artış yüzdesinin ortalaması \%62.16 olarak hesaplanmış, en düşük artış \%33.3 en yüksek artış ise \%100 olarak tespit edilmiştir (Tablo 4). Kol Hareketinin Süratindeki artış yüzdesinin ortalaması \%13.84 olarak hesaplanmış, en düşük artış \%10.97 en yüksek artış ise \%18.70 olarak tespit edilmiştir (Tablo 5). Durarak Çift Bacak Öne Sıçrama artış yüzdesinin ortalaması \%45.46 olarak hesaplanmış, en düşük artış \%9.09 en yüksek artış ise \%133.33 olarak tespit edilmiştir (Tablo 6). Koşu Sürati artış yüzdesinin ortalaması \%12.37 olarak hesaplanmış, en düşük artış \%5.2 en yüksek artış ise \%30 olarak tespit edilmiştir (Tablo 7). Dayanıklııktaki artış yüzdesinin ortalaması ise \%43.14 olarak hesaplanmış, en düşük artış \%20 en yüksek artış ise \%100 olarak tespit edilmiştir (Tablo 8).

Antropometrik ölçümlerde ise araştırmanın zaman sınırlıı̆ından dolayı artışlar çok yüksek oranlarda olmasa da beklenilen düzeydedir. Boy artı̧̧ yüzdesinin ortalaması \%1.15 olarak hesaplanmış, en düşük artış \%0.54 en yüksek artış ise \%2.5 olarak tespit edilmiştir (Tablo 9). Kilo artış yüzdesinin ortalaması \%5.52 olarak hesaplanmış, en düşük artış \%1.96 en yüksek artış ise \%10.25 olarak tespit edilmiştir (Tablo 10). Kulaç artış yüzdesinin ortalamasında ise \% 1.72 olarak hesaplanmış, en düşük artış \%1.22 en yüksek artış ise \%2.72 olarak tespit edilmiştir (Tablo 11). Araştırmamızın bulgularından elde edilen sonuçlara göre tüm OSB'li bireylerin fiziksel uygunluk parametrelerinde artış olduğu görülmüştür. Katıımcıların isimlerinin gizliliğini sağlamak için tablolarda ve analizlerde gerçek isimler yerine kısaltmalar kullanıımıştır. Kısaltmaların başındaki rakamlar araştırmada yer alan OSB'li bireylerin araştırmanın Oyun Konsollu Uyarlanmış Fiziksel Aktivite Antrenman Programına dahil oldukları haftayı " $E$ ve K" kodları ise bireyin cinsiyetini belirtmektedir. 
Tablo 1. Flamingo Denge Testi (sn)

\begin{tabular}{cccc}
\hline Denek Kodu & Ön Test & Son Test & Artış (\%) \\
\hline 1.HK & 1 & 2 & 100 \\
1.HE & 18 & 29 & 61.11 \\
2.HK & 3 & 5 & 66.66 \\
2.HE & 4 & 6 & 50.00 \\
3.HK & 3 & 4 & 33.3 \\
3.HE & 11 & 19 & 72.72 \\
$4 . \mathrm{HK}$ & 2 & 3 & 50.00 \\
$4 . \mathrm{HE}$ & 40 & 59 & 47.50 \\
\hline
\end{tabular}

Tablo 2. Esneklik Ölçüm Testi (cm)

\begin{tabular}{cccc}
\hline Denek Kodu & Ön Test & Son Test & Artış (\%) \\
\hline 1.HK & 5 & 7 & 40.00 \\
$1 . \mathrm{HE}$ & 8 & 12 & 62.50 \\
$2 . \mathrm{HK}$ & 3 & 5 & 66.66 \\
$2 . \mathrm{HE}$ & 5 & 9 & 80.00 \\
$3 . \mathrm{HK}$ & 2 & 3 & 50.00 \\
$3 . \mathrm{HE}$ & 4 & 5 & 25.00 \\
$4 . \mathrm{HK}$ & 4 & 7 & 75.00 \\
$4 . \mathrm{HE}$ & 2 & 4 & 100 \\
\hline
\end{tabular}

Tablo 3. Gövde Kuvveti Ölçüm Testi (Adet)

\begin{tabular}{cccc}
\hline Denek Kodu & Ön Test & Son Test & Artış (\%) \\
\hline 1.HK & 4 & 7 & 75.00 \\
1.HE & 9 & 13 & 44.40 \\
2.HK & 6 & 9 & 50.00 \\
$2 . \mathrm{HE}$ & 1 & 2 & 100 \\
$3 . \mathrm{HK}$ & 2 & 4 & 100 \\
$3 . \mathrm{HE}$ & 5 & 8 & 60.00 \\
$4 . \mathrm{HK}$ & 5 & 9 & 80.00 \\
$4 . \mathrm{HE}$ & 10 & 14 & 40.00 \\
\hline
\end{tabular}


Tablo 4. Bükülü Kol Asılma Ölçüm Testi (sn)

\begin{tabular}{cccc}
\hline Denek Kodu & Ön Test & Son Test & Artış (\%) \\
\hline 1.HK & 6 & 10 & 66.70 \\
1.HE & 1 & 2 & 100 \\
2.HK & 2 & 3 & 50.00 \\
2.HE & 3 & 4 & 33.33 \\
3.HK & 3 & 5 & 66.70 \\
3.HE & 4 & 7 & 75.00 \\
4.HK & 4 & 6 & 50.00 \\
$4 . \mathrm{HE}$ & 9 & 14 & 55.60 \\
\hline
\end{tabular}

Tablo 5. Kol Hareketinin Sürati Ölçüm Testi (sn)

\begin{tabular}{cccc}
\hline Denek Kodu & Ön Test & Son Test & Artış (\%) \\
\hline 1.HK & 48.00 & 39.02 & 18.70 \\
1.HE & 77.00 & 68.55 & 10.97 \\
2.HK & 59.22 & 51.09 & 13.72 \\
2.HE & 58.30 & 51.20 & 12.17 \\
3.HK & 52.55 & 46.30 & 12.43 \\
3.HE & 50.00 & 42.10 & 15.80 \\
4.HK & 46.02 & 40.00 & 13.47 \\
4.HE & 33.90 & 29.32 & 13.51 \\
\hline
\end{tabular}

Tablo 6. Durarak Çift Bacak Öne Sıçrama Ölçüm Testi (cm)

\begin{tabular}{cccc}
\hline Denek Kodu & Ön Test & Son Test & Artı̧̧ (\%) \\
\hline 1.HK & 30 & 36 & 20.00 \\
1.HE & 77 & 84 & 9.09 \\
2.HK & 11 & 16 & 45.45 \\
2.HE & 3 & 7 & 133.33 \\
3.HK & 40 & 46 & 15.00 \\
3.HE & 11 & 15 & 36.36 \\
$4 . \mathrm{HK}$ & 12 & 18 & 50.00 \\
$4 . \mathrm{HE}$ & 12.30 & 19 & 54.47
\end{tabular}

Tablo 7. Koşu Sürati Ölçüm Testi (sn)

\begin{tabular}{cccc}
\hline Denek Kodu & Ön Test & Son Test & Artış (\%) \\
\hline 1.HK & 35 & 30 & 14.28 \\
1.HE & 46 & 39 & 15.21 \\
2.HK & 58 & 55 & 5.20 \\
2.HE & 130 & 103 & 30.00 \\
$3 . \mathrm{HK}$ & 50 & 47 & 6.00 \\
$3 . \mathrm{HE}$ & 48 & 43 & 10.41 \\
$4 . \mathrm{HK}$ & 103 & 58 & 7.90 \\
$4 . \mathrm{HE}$ & 40 & 36 & 10.00 \\
\hline
\end{tabular}


Tablo 8. Dayanıklılı Ölçüm Testi (sn)

\begin{tabular}{cccc}
\hline Denek Kodu & Ön Test & Son Test & Artış (\%) \\
\hline 1.HK & 15 & 19 & 26.66 \\
1.HE & 7 & 9 & 28.57 \\
2.HK & 3 & 5 & 66.66 \\
2.HE & 3 & 4 & 33.33 \\
3.HK & 2 & 4 & 100 \\
$3 . \mathrm{HE}$ & 15 & 18 & 20.00 \\
$4 . \mathrm{HK}$ & 2 & 3 & 50.00 \\
$4 . \mathrm{HE}$ & 25 & 30 & 20.00 \\
\hline
\end{tabular}

Tablo 9. Antropometrik Ölçümler (Boy - cm)

\begin{tabular}{cccc}
\hline Denek Kodu & Ön Test & Son Test & Artış (\%) \\
\hline 1.HK & 1.67 & 1.68 & 0.59 \\
1.HE & 1.72 & 1.73 & 0.58 \\
$2 . \mathrm{HK}$ & 1.55 & 1.58 & 1.93 \\
$2 . \mathrm{HE}$ & 1.46 & 1.48 & 1.36 \\
$3 . \mathrm{HK}$ & 1.60 & 1.64 & 2.50 \\
$3 . \mathrm{HE}$ & 1.83 & 1.84 & 0.54 \\
$4 . \mathrm{HK}$ & 1.65 & 1.67 & 1.21 \\
$4 . \mathrm{HE}$ & 1.84 & 1.85 & 0.54 \\
\hline
\end{tabular}

Tablo 10. Antropometrik Ölçümler (Vücut Ağırlı̆ı̆ - kg)

\begin{tabular}{cccc}
\hline Denek Kodu & Ön Test & Son Test & Artış (\%) \\
\hline 1.HK & 51 & 50 & 1.96 \\
1.HE & 86 & 84 & 2.32 \\
2.HK & 58 & 53 & 8.62 \\
2.HE & 49 & 47 & 4.08 \\
3.HK & 60 & 56 & 6.66 \\
3.HE & 108 & 101 & 6.48 \\
4.HK & 78 & 70 & 10.25 \\
4.HE & 103 & 99 & 3.80 \\
\hline
\end{tabular}

Tablo 11. Antropometrik Ölçümler (Kulaç - cm)

\begin{tabular}{cccc}
\hline Denek Kodu & Ön Test & Son Test & Yüzde Artış \\
\hline 1.HK & 1.55 & 1.59 & 2.58 \\
1.HE & 1.66 & 1.69 & 1.80 \\
2.HK & 1.56 & 1.59 & 1.92 \\
2.HE & 1.47 & 1.51 & 2.72 \\
3.HK & 1.55 & 1.58 & 1.93 \\
3.HE & 1.83 & 1.85 & 1.09 \\
$4 . \mathrm{HK}$ & 1.63 & 1.65 & 1.22 \\
4.HE & 1.83 & 1.86 & 1.63 \\
\hline
\end{tabular}




\section{Tartışma ve Sonuç}

Araştırma, OSB'li bireylerin klasik antrenman programlarına göre farklı bir alternatif olarak düşünülmüș olan Oyun Konsollu Uyarlanmış Bireysel Antrenman Programları ile fiziksel uygunluk düzeylerinin gelişim düzeylerine etkilerini belirlemek amacıyla yapılmıştır. Bu çalışmada OSB'li bireylerin fiziksel olarak gelişim özellikleri ele alındığında eksik kalan ya da aksayan birçok olumsuzluğun giderilmesi bakımından Oyun Konsollu Uyarlanmış Bireysel Antrenman Programlarında kullanılan uygulamaların olumlu etkileri görülmüştür.

Ifadeye dayalı veri toplama araçlarından yüz yüze görüşme yöntemi kullanılarak derinlemesine mülakat görüşmeleri yapıımıştır. Derinlemesine mülakat görüşmeleri antrenör, sınıf öğretmeni ve aileler ile gerçekleştirilmiştir. Her öğrenci için yapılan derinlemesine mülakat görüşmeleri sonunda; antrenörler, sınıf öğretmenleri ve aileler katıımcılardaki gelişmeler hakkında bilgi vermişlerdir. Oyun Konsollu Uyarlanmış Bireysel Antrenman Programı uygulamalarının araştırmaya katılan bireyler üzerinde olumlu etkiler yaptığı, tüm öğrenciler için sosyal uyum düzeylerinde olumlu gelişmeler gerçekleştiği dile getirilmiştir. Tüm katıımcıların ev, okul ve spor salonlarında daha dışa dönük oldukları dile getirilmiştir.

Araştırmanın sonunda yapılan görüşmelerde sorulan sorulara verilen cevaplar değerlendirildiğinde her üç grupta da;

- Yönergelere uydukları

- Akran etkileşiminde artış gösterdikleri,

- S Sınıf içi ve spor salonunda gerçekleşen oyunlara katıım düzeylerinin artığı,

- Katılımcıların spor yapmaya daha istekli oldukları,

- Sınıf içi, spor salonu ve evde daha mutlu oldukları

- Sınıf içi arkadaşlık ilişkilerinde daha olumlu yönde değişiklikler gözlendiğini,

- Dikkat sürelerinde fark edilir şekilde artış olduğu,

- Problem davranış gösteren çocuklarda, problem davranışlarının önemli düzeyde azaldığını,

- El- göz koordinasyonlarında artış olduğu,

- Kalem tutma çizgi çizme davranışının geliştiği,

- Bekleme, sıra alma ve kurallı oyun oynama becerilerinde artış,

Öğrenme becerilerinde artış, bireysel olarak sıçrama, zıplama, top sürme, atma ve tutma becerilerini diğer alanlarda da kullanmaya başladıklarını gözlediklerini dile getirmişlerdir. Yapılan görüşmeler sonucunda ayrıca katıımcıların daha yüksek sosyal beceri düzeyine eriştikleri, sosyal uyum düzeyleri yükseldikçe problem davranışları daha azaldığı tespit edilmiştir. Farklı değişkenlerin sosyal uyum üzerindeki etkisi incelendiğinde motor beceri, fiziksel aktiviteye katıım ve problem davranışların azalmasının sosyal uyum üzerinde etkili olduğu tespit edilmiştir.

İhan'ın (2009) çalışmasında, özel çocukların, özel eğitim aldıkları rehabilitasyon merkezleri ve okullarda katıldıkları benzer aktiviteler arasında, beden eğitimi ve sporun yaklaşık yüzde onluk bir oran ile dördüncü sırada yer aldığını dile getirmişlerdir. Çocuklara, özel eğitimleri dahilinde sunulan bu tür paralel aktivitelerin kapsamları ve çeşitliliği itibari ile okulların eğitim kadrosuna ve fiziki şartlarına bağlı olabileceği şeklinde yorumlanmıştır. Araştırmada kullanılan oyun konsollu fiziksel aktivite; uzman kadronun kullanım kolaylığı yönünden tercih edebileceği ve fiziki şartları uygun olmayan merkezler için ise fiziksel aktivite yaptırabilmek için inanılmaz kolaylık sağlayacağı için tercih sebebi olması gerektiği düşünülerek spora ayrılan yüzde 10'luk dilimi arttırmayı amaçlamaktadır.

Bu kapsamda; OSB'li bireyler için; gruba ait olma duygusunu geliştirmek, zihinsel beceriler kazandırmak, fiziksel uygunluğu arttırmak gibi birçok amaca hizmet ettiği bilinmektedir. Dahası, fiziksel aktivite, genellemeler yoluyla günlük yaşamını ve diğer eğitsel faaliyetleri olumlu etkileme potansiyeline sahiptir. Çocuğun hareket etmesi hem kendisi hem de çevresi için önemlidir. Spor; OSB'li bireylerde bazen tıpkı bir dil gibi iletişim yolu olmaktadır. Araştırmalar sonrasında sporun, OSB'li bireyin çevresiyle bağlantı kurduğu, kendini anlatabilmeyi başardığı bir araç haline dönüştüğü görülür. 


\section{Öneriler}

14 haftalık antrenman sürecinde bile anlamlı sonuçlar veren bu programın Türkiye'de yapılacak olan daha kapsamlı diğer araştırmalarda 6 aylık veya 1 senelik periyotlar ile uzun vadeli gerçekleştirilerek; genelleme etkisinin ve dikkat dağınıklığındaki ve stereotipik hareket düzeylerindeki değişimlerin incelenmesinin alan yazına ciddi katkı sağlayacağı düşünülmektedir. Araştırmanın sonuçları ışığında Oyun Konsollu Uyarlanmış Bireysel Antrenman Programı'ın Türkiye'deki kısıtlı sayıdaki OSB'li bireyde uygulanabilirliği test edilmiş ve sporcuların 14 hafta gibi kısa süreli antrenman programına katılmış olmasına rağmen olumlu yönde anlamlı yükselişler gösterebildikleri tespit edilmiştir. Bulguların bir veya iki dönemlik araştırmalar ile geliştirilerek olumlu sonuçların teyidi halinde Milli Eğitim Bakanlığı'ın Beden Eğitimi programına dahil edilmesi önerilebilir. Ayrıca Spor Bakanlığının engelli bireylere ait spor kulüplerinde de etkili olarak uygulanabilmesi için tavsiye edilebilecektir. Rehabilitasyon merkezlerindeki kısıtı yer sorunundan dolayı Aile ve Sosyal Politikalar Bakanlığının vereceği destek ile spor odaları olarak yürürlüğe konulması da önerilebilecektir.

\section{Bilgi Notu}

Bu araştırma Marmara Üniversitesi Bilimsel Araştırma Projeleri Birimi'nden (BAPKO) SAG-C-DRP-120417-0153 nolu projesi olarak finansal olarak desteklenmiştir.

\section{Kaynakça}

Akyol, A.G.A., Bilgiç, A.G.P. \& Ersoy, G. (2008). Fiziksel Aktivite, Beslenme ve Sağlıklı Yaşam. Ankara: Klasmat Matbaacilik.

Alp, H. \& Çamlıyer, H. (2016) Otistik Çocuklarda Görülen Davranış Problemlerinin Düzeltilmesiyle Hareket Eğitimi ve Fiziksel Aktivitelerin Illişkisi. Eğitim ve Öğretim Araştırmaları Dergisi, 5(2/26): 252-264.

Bahrami, F., Movahedi, A., Marandi, S.M. \& Abedi, A. (2012). Kata technique straining consistently decreases stereotypy in children with autism spectrum disorder. Research in develop mental disabilities, 33(4), 1183-1193. Doi: 10.1016 / j.ridd.2012.01.018

Bumin, G., Uyanık, M., Yılmaz, I., Kayıhan, H. \& Topçu, M. (2003). Hydro therapy for Rett syndrome. Journal of rehabilitationmedicine, 35(1), 44-45. Doi: 10.1080 / 16501970306107

Cottenceau, H., Roux, S., Blanc, R., Lenoir, P., Bonnet-Brilhault, F., \& Barthélémy, C. (2012). Quality of life of adolescents with autism spectrum disorders: comparison to adolescents with diabetes. European child \& adolescent psychiatry, 21(5), 289-296. Doi: 10.1007 / s00787-012-0263-Z

Ilthan, L. (2009). Zihinsel Engelli Çocuğu Olan Anne-Babaların Çocuklarının Özel Eğitimleri Sürecinde Beden Eğitimi Ve Spor Etkinliklerine Yaklaşımlarının Değerlendirilmesi. Niğde Universitesi Beden Eğitimi ve Spor Bilimleri Dergisi, 3(1), 38-48.

Kern, L., Koegel, R. L., \& Dunlap, G. (1984). The influence of vigorous versus mild exercise on autistic stereotyped behaviors. Journal of autism and developmental disorders, 14(1), 57-67. Doi: 10.1007 / BF02408555

Kırcaali -iftar, G. \& Tekin, E. (1997). Tek denekli araştırma yöntemleri. Ankara: Türk Psikologlar Derneği Yayınları.

Kırcaali-iftar, G. (2012). Otizm spektrum bozukluğuna genel bakış. Otizm spektrum bozukluğu olan çocuklar ve eğitimleri içinde, 17-44.

Korkmaz, O. T., \& Diken, I. H. (2010). Effectiveness of the approaches used in reducing the stereotypical behaviors: A descriptive meta-analysis. Ankara Üniversitesi Eğitim Bilimleri Fakültesi Özel Eğitim Dergisi- Ankara Unıversıty Faculty of Educatıonal Scıences Journal of Special Education, 11(2), 1-12. 
Lang, R., Koegel, L. K., Ashbaugh, K., Regester, A., Ence, W., \& Smith, W. (2010). Physical exercise and individuals with autism spectrum disorders: A systematic review. Research in Autism Spectrum Disorders, 4(4), 565-576. Doi: 10.1016/j.rasd.2010.01.006

Lee, J., \& Porretta, D. L. (2013). Document analysis of sports literature for individuals with disabilities. Perceptual and motor skills, 116(3), 847-858. Doi: 10.2466 / 15.06.PMS.116.3.847-858

Menear, K. S., \& Neumeier, W. H. (2015). Promoting physical activity for students with autism spectrum disorder: Barriers, benefits, and strategies for success. Journal of Physical Education, Recreation and Dance, 86(3), 43-48. Doi: 10.1080/07303084.2014.998395

Müller-Riemenschneider, F., Nocon, M., Hiemann, T., Thalau, F., Roll, S., \& Willich, S. N. (2008). Association of physical activity with all-cause and cardiovascular mortality: a systematic review and meta-analysis. European Journal of Cardiovascular Prevention \& Rehabilitation, 15(3), 239-246. Doi: 10.1097/HJR.ob013e3282f55eog

Nicholson, H., Kehle, T. J., Bray, M. A., \& Heest, J. V. (2011). The effects of antecedent physical activity on the academic engagement of children with autism spectrum disorder. Psychology in the Schools, 48(2), 198-213. Doi: 10.1002 / pits.20537

Olin, S.S. et all. (2017). The Effects of Exercise Dose on Stereotypical Behavior in Children with Autism. Medicine \& Science in Sports \& Exercise, 49(5): 983-990. Doi: 10.1249 / MSS.0000000000001197

Pitetti, K. H., Rendoff, A. D., Grover, T., \& Beets, M. W. (2007). The efficacy of a 9-month treadmill walking program on the exercise capacity and weight reduction for adolescents with severe autism. Journal of Autism and Developmental Disorders, 37(6), 997-1006. Doi: 10.1007 / s10803-006-0238-3

Powers, S., Thibadeau, S., \& Rose, K. (1992). Antecedent exercise and its effects on self-stimulation. Behavioral Interventions, 7(1), 15-22. Doi: 10.1002/bin.2360070103

Read, P. D., Factor, D. C., Freeman, N. L., \& Sherman, J. (1988). The effects of physical exercise on three autistic and developmentally disordered adolescents. Therapeutic Recreation Journal, 22(2), 47-56.

Robledo, J. A., \& Donnellan, A. M. (2008). Properties of supportive relationships from the perspective of academically successful individuals with autism. Intellectual and Developmental Disabilities, 46(4), 299-310. Doi: 10.1352/1934-9556(2008)46[299:POSRFT]2.0.CO;2

Ruef, M. B., \& Turnbull, A. P. (2002). The perspectives of individuals with cognitive disabilities and/or autism on their lives and their problem behavior. Research and Practice for Persons with Severe Disabilities, 27(2), 125-140. Doi: 10.2511/ rpsd.27.2.125

Russell, G., Kelly, S., \& Golding, J. (2010). A qualitative analysis of lay beliefs about the aetiology and prevalence of autistic spectrum disorders. Child: care, health and development, 36(3), 431-436. Doi: 10.1111 / j.1365-2214.2009.00994.X

Seabra, A., Mendonça, D., Maia, J., Welk, G., Brustad, R., Fonseca, A. M., \& Seabra, A. F. (2013). Gender, weight status and socioeconomic differences in psychosocial correlates of physical activity in schoolchildren. Journal of Science and Medicine in Sport, 16(4), 320-326. Doi: 10.1016 / j.jsams.2012.07.008

Sorenson, C.A. \& Zarrett, N. (2014). Benefits of Physical Activity for Adolescents with Autism Spectrum Disorders: A Comprehensive Review. Review Journal of Autism and Developmental Disorders. Doi: 10.1007 / s40489-014-0027-4

Srinivasan, S. M., Pescatello, L. S., \& Bhat, A. N. (2014). Current perspectives on physical activity and exercise recommendations for children and adolescents with autism spectrum disorders. Physical therapy, 94(6), 875-889. Doi: 10.2522 / ptj.20130157

Tekin, E. (2000). Karşılaştırmalı tek-denekli araştırma modelleri. Ankara Üniversitesi Eğitim Bilimleri Fakültesi Özel Eğitim Dergisi, 2(4), 1-12.

Tekin-iftar, E., \& Kırcaali-iftar, G. (2006). Özel eğitimde yanlışıı öğretim yöntemleri. Nobel Yayın Dağıtım.

Tekin-iftar, E., \& Değirmenci, H. D. (2012). Otizm spektrum bozukluğu olan çocukların öğretimi. Otizm spektrum bozukluğu olan çocuklar ve eğitimleri içinde, 267-313.

T.C. Sağlık Bakanlığı, (2014). Türkiye Fiziksel Aktivite Rehberi. Yaşlılarda Fiziksel Aktivite. Ankara.

Todd, T., \& Reid, G. (2006). Increasing physical activity in individuals with autism. Focus on autism and other developmental disabilities, 21(3), 167-176. Doi: 10.1177 / 10883576060210030501

Yarımkaya, E., İlhan, E. L., \& Karasu, N. (2017). Akran aracılı uyarlanmış fiziksel aktivitelere katılan otizm spektrum bozukluğu olan bir bireyin iletişim becerilerindeki değişimlerin 
incelenmesi. Ankara Üniversitesi Eğitim Bilimleri Fakültesi Özel Eğitim Dergisi, 18(02), 225-252. Doi: 10.21565/ozelegitimdergisi.319423

Yılmaz, I., Yanardağ, M., Birkan, B., \& Bumin, G. (2004). Effects of swimming training on physical fitness and water orientation in autism. Pediatrics International, 46(5), 624-626. Doi: 10.1111 / j.1442-200x.2004.01938.x 